Miao, C., Humphrey, R. H., \& Qian, S. (in press, 2021). Emotional Intelligence and Job Performance in the Hospitality Industry: A Cross-Cultural Qualitative and Quantitative Review. International Journal of Contemporary Hospitality Management. DOI 10.1108/IJCHM-04-2020-0323

Title: Emotional intelligence and job performance in the hospitality industry: A meta-analytic review

\begin{abstract}
Purpose - Hospitality workers are emotional labor workers because they must display appropriate emotions to their customers to provide outstanding service. Emotional intelligence (EI) helps employees regulate their emotions and display appropriate emotions, and hence should help hospitality workers provide outstanding service. However, the strength of the relationship between EI and hospitality workers' job performance substantially varied across studies. Hence, the goal of the present study is to clarify the mixed findings and to examine if EI can improve hospitality workers' job performance.

Design/methodology/approach - A meta-analysis was performed to investigate the relationship between EI and hospitality workers' job performance as well as the moderators which condition this relationship.

Findings - The present meta-analysis indicated that (1) EI is positively related to hospitality workers' job performance ( $\hat{\rho}=0.54)$; (2) the relationship between EI and hospitality workers' job performance is stronger when the percentage of married subjects is low and in feminine cultures; and (3) this relationship does not differ between male-dominated and female-dominated studies, across educational levels, between collectivistic and individualistic cultures, between low and high power distance cultures, and between low and high uncertainty avoidance cultures.
\end{abstract}

Implications - Our study uncovers theoretically important moderators that contribute to crosscultural research, work-family literature, and gender-related literature in hospitality research.

Originality/value - The present study builds a theoretical foundation and performs a metaanalysis to elucidate the relationship between EI and hospitality workers' job performance and to identify the moderators which condition this relationship.

Keywords - emotional intelligence; job performance; hospitality industry; meta-analysis 


\title{
Emotional Intelligence and Job Performance in the Hospitality Industry:
}

\author{
A Meta-Analytic Review \\ Engage your emotions at work. Your instincts and emotions are there to help you. \\ - Sir Richard Branson
}

\section{Introduction}

The rise in the hospitality industry has resulted in substantial growth in publication opportunities (Kim et al., 2018) as well as in the demand for talented employees with the right skills for hospitality work (Baum, 2019). Hospitality workers play a very important role in ensuring the quality of service because they must perform well enough to ensure their guests feel satisfied, respected, and valued (Langhorn, 2004; Scott-Halsell et al., 2008). Hospitality workers' job performance influences customers' perception of service quality and collectively has an impact on organizational effectiveness ( $\mathrm{Li}$ and Huang, 2017). A growing body of literature has begun to examine the antecedents of hospitality workers' job performance, but more research remains to be done ( $\mathrm{Li}$ and Huang, 2017).

Employees in the hospitality industry are considered as "emotional laborers" because their work entails intensive direct customer contact and they have to conform to organizational display rules to express desirable emotions (e.g., friendliness, cheerfulness, and enthusiasm) during interpersonal interactions (Moreo et al., 2019; Shani et al., 2014). In a traditional hospitality job which requires "service with a smile", hospitality workers must be aware of their own emotions, perceive customers' emotions (e.g., better read customers' facial expressions and body language), be empathic to customers' feelings, and regulate their own emotions to effectively manage and facilitate their interactions with their customers (Lee and Ok, 2012). 
A key aspect of emotional intelligence (EI) is the ability to read and understand other's emotions and feelings, thus EI can help hospitality workers perceive customers' emotions. Hence, emotional intelligence (EI) has been one of the most frequently studied antecedents of emotional labor in the hospitality industry (Lee and Madera, 2019). In addition, authentic leaders are better at helping their hospitality workers perform emotional labor (Wang and Xie, 2020), and EI is strongly related to authentic leadership (Miao et al., 2018a). Perhaps this is because EI helps people manage their own and others' emotions. EI can help hospitality workers manage their own emotions under difficult working conditions and can also help them soothe irritated and unhappy customers. EI represents "a constellation of behavioral dispositions and self-perceptions concerning one's ability to recognize, process, and utilize emotion-laden information" (Petrides et al., 2004, p. 278).

Research has demonstrated that EI is a popular construct (Ashkanasy et al., 2017) and predicts a series of important workplace outcomes, such as workers' job attitudes, workers' task and contextual performance, leadership, and health and well-being (Boyatzis et al., 2012; Cherniss, 2001; Goleman, 1995; Goleman et al., 2013; O’Boyle et al., 2011; Martins et al., 2010; Miao et al., 2016, 2017a, 2017b, 2018a; 2018b; Schutte et al., 2007). Research has also supported the validity of the factor structure of EI and the incremental variance contributed by EI (e.g., Andrei et al., 2016; O’Boyle et al., 2011; Siegling et al., 2015; van der Linden et al., 2017). The concept of EI has gained a tremendous amount of attention in the hospitality literature (e.g., Koc and Boz, 2020; Langhorn, 2004; Lee and Ok, 2012; Scott-Halsell et al., 2008) inasmuch as EI captures a set of important skills that hospitality workers need to enhance their job performance (Scott-Halsell et al., 2008). Further, due to the rapid growth of the field of 
hospitality, Kim et al. (2018) called for more meta-analysis papers to synthesize the literature. A meta-analytic integration is required to sort out the complexity in the literature.

The first purpose of this meta-analysis is to sort out the mixed findings in this line of literature and to examine the overall effect of EI on hospitality workers' job performance. For example, Hsu et al. (2016) reported a correlation coefficient of 0.80 for this relationship whereas Tekin and Gündoĝan (2017) found that the range of the correlations between each EI dimension and hospitality workers' job performance is from 0.095 to 0.355 . Viglia and Rodrigo (2020) have posited that because the hospitality industry has high levels of interactions between customers and employees that $\mathrm{EI}$ is an indispensable aspect of service interactions. Knowing the main performance effect of EI enables practicing managers to make well-informed, evidence-based personnel decisions. For example, managers may properly allocate companies' resources to administer EI training sessions to their employees and/or incorporate EI tests during the personnel selection processes to hire emotionally intelligent employees (Boyatzis, 2009; Min, 2011).

Our second major purpose is to examine cross-cultural and demographic moderators of the EI—hospitality job performance relationship. Emotional norms vary across cultures (Gunkel et al., 2014), and preliminary findings regarding the role of EI in the hospitality industry indicate that there may be cross-cultural differences in terms of the effect size of EI (e.g., Walsh et al., 2015; Wen et al., 2019). Since the samples were drawn from different cultures, meta-analytic techniques can be applied to investigate how the performance effect of EI is conditioned by national cultural dimensions. This study will also examine how demographic differences condition the effect of EI on hospitality workers' job performance (e.g., Gültekin and Icigen, 2019). The hypothesized relationships among variables are shown in Figure 1. 


\section{Insert Figure 1 about here}

\section{Theory and Hypotheses}

\section{Emotional Intelligence}

There are two major differences in the way EI measures are conceptualized: ability EI versus trait EI (Petrides, 2017). Ability EI conceptualizes EI as a type of intelligence and ability

EI measures resemble other cognitive ability measures which include "objective" right or wrong items to evaluate an individual's EI (Mayer et al., 2003). Trait EI conceptualizes EI as having emotion-related dispositions and self-perceptions of emotional abilities which can be measured based on self-reports just like the way that personality traits are measured (Petrides and Furnham, 2001; Petrides et al., 2007, 2016). For example, trait EI can be construed as a comprehensive representation of the affective parts of personality that consists of four dimensions: well-being, self-control, emotionality, and sociability (Petrides et al., 2016). Since all the existing empirical studies which examined the relationship between EI and hospitality workers' job performance used trait EI scales to measure EI, we only focused on trait EI in the present study.

\section{EI and Hospitality Workers' Job Performance}

EI is important to individual task performance across a wide range of occupations, as shown by meta-analysis (O’Boyle et al., 2011). Moreover, another meta- analysis found that EI is positively related to individual organizational citizenship behavior and negatively related to counterproductive work behavior, two other important types of performance (Miao et al., 2017b). In addition, meta-analysis has found that leader's EI is positively related to subordinate's task performance and organizational citizenship behavior (Miao et al., 2018b). There is also reason to believe EI may be particularly important in the hospitality industry. This is because many jobs in 
the hospitality industry are especially high in emotional labor demands and display rules (Moreo, et al., 2019).

As Liu and Cho (2018) observed, display rules refer to organizational standards that regulate the emotions that employees should portray as part of their job duties (Ashforth and Humphrey, 1993), and these display rules are especially common in the hospitality industry. Although it is commonly recognized that these display rules apply to frontline service workers, leaders also perform emotional labor (Humphrey et al., 2008), and Liu and Cho found that display rules positively influenced work engagement for hotel managers as well as non-managers. Of particular importance, they also found that EI increased the beneficial effect of display rules on work engagement for hotel managers with high EI. In another study, Genc and Kozak (2020) found that restaurant managers' EI increased both service employees' performance as well as kitchen staff's performance. Their study is important because it shows that the effects of EI in the hospitality industry are not restricted to frontline service employees but apply to other staff as well. Moreover, they convincingly argued that kitchen staff also engaged in emotional labor when they produce aesthetically pleasing food in terms of both taste and appearance. Thus, we believe that it is particularly important to study the effects of EI on performance among hospitality workers because display rules and emotional labor demands are especially high in the hospitality industry.

The jobs in the hospitality sector are emotionally demanding and stressful in general because hospitality workers inevitably have to continuously manage their true feelings and emotional displays, particularly when dealing with difficult, moody customers (Walsh et al., 2015). Prior research has shown that emotionally savvy hospitality workers are able to use their EI to read customers' emotions, engage with customers, emphasize with customers, display and 
maintain positive emotions, and quickly bounce back from mood-dampening events (Walsh et al., 2015). They behave in socially effective ways which reflect their dependability, sociability, and friendliness (van der Linden et al., 2017). Prior research has shown that the effect of self-report EI will be intensified when the situations call for a greater amount of emotional labor (Miao et al., 2017a). Therefore, the performance effect of EI should be particularly relevant in hospitality settings where emotional labor demands are high (Viglia and Rodrigo, 2020).

The hospitality industry, like any industry, can be filled with frustrating work events. Employees react to these events by using three types of emotional labor. They can use surface acting to display emotions they do not really feel (i.e., faking their emotions), or they can use deep acting to summon up and actually feel the appropriate emotions they want to display. In addition, employees may also use a third form of emotional labor, genuine and natural emotional labor, if they naturally feel the appropriate emotions for the work situation they are in (Ashforth and Humphrey, 1993). Although surface acting can lead to negative outcomes such as emotional dissonance and feelings of depersonalizations, reviews have demonstrated that deep acting and natural and genuine emotional labor can improve employee well-being and job performance (Humphrey et al., 2015). In a groundbreaking study, Lee and Ok (2012) demonstrated that emotional intelligence (EI) can help hospitality workers reduce the negative emotions that come from surface acting and summon up the emotional effort necessary to use the positive forms of emotional labor. They found that EI was negatively related to emotional dissonance and to depersonalization and was positively related to emotional effort (a measure of deep acting) and to personal accomplishment.

Job satisfaction increases organizational commitment in the hospitality industry (Kong et al., 2018). EI may also help workers in the hospitality industry by increasing their job 
satisfaction, which may in turn increase their performance. For example, EI may help hospitality workers deal with incivility from customers (Kim and Qu, 2019) or with other types of burnout (Kong et al., 2021). Regarding occupations overall, meta-analyses have confirmed that EI is positively related to employees' job satisfaction and organizational commitment and is negatively related to turnover intentions (Miao et al., 2017a). Likewise, meta-analysis has also demonstrated that leaders' EI is positively related to employees' job satisfaction (Miao et al., 2016).

Regarding the hospitality industry, Han et al. (2017) found that restaurant managers with high EI increased employee satisfaction, which resulted in higher service performance. In a similar vein, Chen and Wang (2019) found that EI is positively related to job satisfaction and moderates the association between workplace incivility and job satisfaction for tourist hotel chefs. Likewise, Jung and Yoon (2016) found in a study of food and beverage hospitality workers that EI was positively correlated with job satisfaction and helped employees cope with work stress. Moreover, they argued that by reducing stress and improving job satisfaction that EI should improve performance as well. For example, a study of restaurant frontline service employees found that emotion regulation ability (a key component of EI) moderated the effects of workplace incivility on emotional exhaustion and perceived service performance (Cho et al., 2016).

Emotionally intelligent hospitality workers can implement effective emotional labor strategies, such as deep acting, to express appropriate and engaging emotions to their customers (Choi et al., 2019; Wen et al., 2019). They can regulate their emotions to exhibit genuine positive emotional displays (e.g., smiling, cheerfulness, optimism, and enthusiasm) to delight others during the service delivery processes (Tsaur and $\mathrm{Ku}, 2019$ ). Thus, hospitality workers' EI 
is a very important trait which they can harness to enhance their job performance. Hence, the following hypothesis:

Hypothesis 1: Hospitality workers' EI is positively related to their job performance.

\section{Demographic Moderators}

Gender. There is a growing body of studies which examined the role of gender in EI research. Males and females may differ in their use of EI because of educational and socialization practices that encourage women to adopt caring roles that require EI skills, whereas men may be encouraged to act tough and suppress their emotions. Considerable research on hospitality indicates that gender acts as a moderator for a variety of important relationships, such as between transformational leadership and quality of work life (Kara et al., 2018). Another study in the hospitality industry found that women rated their job satisfaction lower than men did on being able to use their abilities while at work (Kara et al., 2012). Because EI is an important ability, this suggests that there may be gender differences in the relationship between EI and hospitality workers' job performance. In a study of hotel employees, Jung and Yoon (2014) found partial support for gender as a moderator of EI to emotional labor relationships, with the effects of others' emotion appraisal (a subscale of EI) on surface acting significantly stronger for women. However, not all studies have found gender differences in EI. A study designed specifically to test for gender differences found no support for the hypothesized female superiority in emotional competencies (Taylor and Hood, 2011). Hence, it is important to test whether female hospitality workers may benefit more from EI to affect their job performance. We suggest the following hypothesis:

Hypothesis 2: The relationship between hospitality workers' EI and job performance is stronger in female-dominated studies than in male-dominated studies. 
Education. Higher education trains individuals to have the general knowledge and skills needed to perform well (Døving and Gooderham, 2008). Human capital theory suggests that individuals with higher levels of competencies, skills, and knowledge will perform better at their jobs (Martin et al., 2013). There are two routes to successful job performance, one through cognitive ability and complex task performance, and the other through empathic and emotionally intelligent interpersonal interactions with others (Kellett et al., 2002). Highly educated and trained hospitality workers may rely on their formal job skills and training to aid their performance, whereas less educated employees may have to depend more on their interpersonal and emotional skills. Due to these reasons, we expect that the relationship between hospitality workers' EI and job performance is stronger when subjects are less educated.

Researchers in hospitality have also drawn upon Conservation of Resources (COR) theory, which was developed by Hobfoll (1989), to explain EI relationship. According to COR theory, employees have a variety of resources, including social, mental, and physical, to help them cope with work demands. Researchers have also found that EI acts as a type of resource that helps workers deal with the stresses and demands of hospitality work (Choi et al., 2019; Lee and Ok, 2012,2014). According to COR theory, education is another type of resource that could be used to help employees cope with stressful work demands. Because workers try to conserve their resources, COR theory implies that people who draw upon one resource may in some circumstances be less likely to draw upon their other resources. For example, in some cases people may use either their EI skills or their educational skills to help them perform their jobs. Because less educated employees would not be able to draw upon their educational resources as much, they would need to rely more heavily on utilizing their EI skills to help them cope with 
the stresses of service work and other hospitality work. This suggests that educational levels may operate as a moderator of the $\mathrm{EI}-\mathrm{job}$ performance relationship.

Hypothesis 3: The relationship between hospitality workers' EI and job performance is stronger when subjects are less educated than when subjects are well educated.

Marital status. According to COR theory, being married may also be considered as a resource (Hobfoll, 1989). Reviews have consistently found that married people are happier than single people, are physically healthier, and are better off financially (Waite and Gallagher, 2000). In addition, married mothers, compared to single mothers, are less likely to be depressed, less likely to report high levels of chronic stress, and are more likely to report higher levels of social support and social involvement (Cairney et al., 2003). Married couples may also experience work-family enrichment that increases their marital satisfaction (van Steenbergen et al., 2014). Consequently, it is likely that married hospitality workers experience less stress and depression, less work-family conflict, less financial pressures and have better overall social support and wellbeing. In addition, it is possible that unmarried people in long-term, stable, partnership relations might accrue some of the same benefits as married people; however, because the studies in our meta-analysis only categorized people as either married or unmarried, we were not able to test for this. EI helps people cope with stress and negative events, and meta-analyses have demonstrated that people high on EI have better mental and physical health (Martins et al., 2010).

Thus, it is likely that EI would be especially helpful for single hospitality workers because they lack the social, emotional, and financial support that comes with being married. As with education, COR theory suggests that workers try to conserve resources, so people who draw upon their partner for social support and for coping with work stress may feel less of a need to draw upon their EI competencies to help them. This suggests that marital status may act as a 
moderator of the EI-job performance relationship. However, it is unclear what the relationship between marital/partner status might be because it is possible that people with higher EI might be more likely to be in long-term partnership relationships. Also, married people or those in longterm partnership relationships might still use their EI skills to achieve high levels of performance. Thus, it is important to investigate the effects of marital/partner status on the EI-performance relationship. We therefore suggest the following hypothesis:

Hypothesis 4: The relationship between hospitality workers' EI and job performance is stronger when percent of married subjects is low than when percent of married subjects is high.

\section{National Cultural Moderators}

Trait activation theory states that traits are more likely to predict performance when a context is pertinent to a trait, meaning that traits will be activated (i.e., individuals' expression of traits) when a context contains trait-relevant cues (Tett and Burnett, 2003). National cultures are known to contain salient trait-relevant situational cues that will activate the expression of traits (Choi et al., 2015). Therefore, we formulate the hypotheses regarding the moderator role of national cultural dimensions based on trait activation theory.

Individualism versus collectivism. Individualistic cultures are characterized by loose interpersonal ties and everyone is anticipated to take care of themselves and their immediate family (Hofstede, 2011). In contrast, collectivistic cultures are characterized by strong, cohesive groups and individuals from these cultures value harmony, relationship building, and integration into groups (Hofstede, 2011). Hospitality workers from collectivistic cultures can better utilize their EI because collectivistic cultures call for more frequent use of EI and regulation of emotions to minimize conflicts to not only benefit their own performance but also maintain harmony with others (Gunkel et al., 2014). We thus formulate the following hypothesis: 
Hypothesis 5: The relationship between hospitality workers' EI and job performance is stronger in collectivistic cultures than in individualistic cultures.

Masculinity versus femininity. Masculine cultures are characterized by competitiveness and assertiveness and feminine cultures are characterized by modesty, caring, and sympathy for the weak (Hofstede, 2011). The expression of EI is less likely to be activated in masculine cultures. Individuals from such cultures do not use their EI to regulate their emotions as much as do individuals from feminine cultures because outward, direct expression of emotions, or sometimes even being aggressive, is acceptable in masculine cultures (Gunkel et al., 2014). In contrast, the hospitality workers from feminine cultures, where trait-relevant cues that call for the utilization of EI are present and salient, can better use their EI to manage their emotions to display more favorable, proper emotions to their customers, thus enhancing their customers' perception of service quality and boosting their job performance. We therefore advance the following hypothesis:

Hypothesis 6: The relationship between hospitality workers' EI and job performance is stronger in feminine cultures than in masculine cultures.

Power distance. Power distance refers to the degree to which less powerful individuals accept unequal power distribution (Hofstede, 2011). In high power distance cultures where hospitality workers' role in a given organization is based on compliance/obedience, hospitality workers' EI is less likely to be activated because one cannot effectively use their EI to freely and openly express their emotions (Gunkel et al., 2014; Hofstede, 2011). In addition, individuals are less sensitive to emotions in high power distance cultures, further leading to decreased utility of EI, the deactivation of EI, and to a weaker EI effect on job performance (Kirkman et al., 2009). Thus, we offer the following prediction: 
Hypothesis 7: The relationship between hospitality workers' EI and job performance is stronger in low power distance cultures than in high power distance cultures.

Uncertainty avoidance. Uncertainty avoidance refers to a society's level of tolerance for ambiguity and level of comfort in unstructured situations which are novel and unusual (Hofstede, 2011). We argue that EI is likely to be activated in high uncertainty avoidance cultures where individuals have a strong need for clarity and feelings of ambiguity are considered as a threat that must be dealt with. Hence, hospitality workers from such cultures depend heavily on their EI to be emotionally expressive to display proper emotions to ensure others can clearly understand them without any confusion (Gunkel et al., 2014; Hofstede, 2011). Cultural norms in high power distance countries allow hospitality workers to effectively use their EI to facilitate their job performance and service quality by being emotionally expressive to their customers. We therefore provide the following hypothesis:

Hypothesis 8: The relationship between hospitality workers' EI and job performance is stronger in high uncertainty avoidance cultures than in low uncertainty avoidance cultures.

\section{Method}

\section{Literature Identification}

We used a combination of keywords to search for relevant articles, such as emotional intelligence, emotional competency, performance, hospitality, tourism, travel, and hotel. The search date was set from the earliest date of each database and journal to year 2019. First, we performed computerized search of electronic databases, including ABI/INFORM, EBSCO Host, ProQuest Dissertations and Theses, PsycNET, and Web of Science. Pertinent management, hospitality, tourism, and psychology journals were searched, including Academy of Management Journal, Administrative Science Quarterly, Annals of Tourism Research, Cornell Hospitality 
Quarterly, International Journal of Contemporary Hospitality Management, International Journal of Hospitality Management, Journal of Applied Psychology, Journal of Hospitality Marketing \& Management, Journal of Hospitality \& Tourism Research, Journal of Management, Journal of Management Studies, Journal of Occupational and Organizational Psychology, Journal of Organizational Behavior, Journal of Quality Assurance in Hospitality \& Tourism, Journal of Personality and Social Psychology, Journal of Service Research, Journal of Travel Research, Journal of Travel \& Tourism Marketing, Journal of Vocational Behavior, Journal of Vacation Marketing, Organizational Behavior and Human Decision Processes, Organization Science, Personnel Psychology, Tourism Analysis, and Tourism Management. We also searched Google, Google Scholar, and Social Science Research Network to not only ensure the comprehensiveness of literature search but also capture unpublished studies. The search approaches we used are comparable to the recommended approaches which were used in several recent meta-analyses in the hospitality literature (e.g., Chang et al., 2020; Gui et al., 2020; Xu and Cao, 2019). Our initial search returned 868 articles for possible inclusion.

\section{Inclusion Criteria}

We set three inclusion criteria to winnow the articles we identified. First, the included studies must be quantitative and empirical. Second, the included studies had to provide at least one correlation coefficient between EI and job performance or report statistics that would allow us to convert them into correlation coefficients via the methods developed by Lipsey and Wilson (2001) and/or Peterson and Brown (2005). Third, the included studies had to sample hospitality workers. Two authors of the present study who have Ph.D. degrees and experience in performing meta-analyses screened the articles identified via initial search based on the aforementioned 
inclusion criteria. A total of 15 studies (that contain a sample size of 3,086 hospitality workers) were considered eligible for inclusion.

Although the number of studies in our meta-analysis is not large, it is still considered as acceptable and comparable to other published meta-analyses in major hospitality and tourism journals. For example, Nisa et al.'s (2017) meta-analysis only covered 9 papers to examine what promotes sustainable hotel guest behaviors. The results of our meta-analysis can provide an interim evaluation of literature, clarify the areas where more research is needed, and set the stage for future research (Miao et al., 2017d). We provided the references for the included studies in our meta-analysis in the References section (see the references marked with *).

\section{Coding Procedures}

We first coded the main effect of EI on hospitality workers' job performance. We coded trait EI in the current study because all the available empirical studies on the association between EI and hospitality workers' job performance employed trait EI scales to measure EI. Trait EI conceptualizes EI as self-perceptions of emotional abilities and emotion-related dispositions which can be measured via self-reported ratings (e.g., Petrides and Furnham, 2001; Petrides et al., 2016). Service performance and other task performance measures were routinely used to measure hospitality workers' job performance in the literature, and we coded and considered these performance outcomes. We also coded a set of moderators. (1) gender: we followed prior studies by coding the percent of male subjects (e.g., Bae et al., 2014) and performed a median split to allocate samples into male-dominated and female-dominated subgroups; (2) education: we coded the percent of subjects having college level degree or above and then conducted a median split to assign samples into high and low education level subgroups; (3) marital status: we coded the percent of subjects who are married and performed a median split to allocate 
samples into high and low subgroups; and (4) cultural dimensions: we followed Hofstede cultural dimensions (Hofstede et al., 2010) to code studies across four cultural dimensions. Table 1 was provided to summarize the variable coding and definitions for the clarity of reporting.

\section{Insert Table 1 about here}

\section{Meta-Analytic Procedures}

We performed meta-analyses in line with Schmidt and Hunter (2015). We corrected measurement errors and calculated $\hat{\rho}$ (corrected sample-size-weighted mean correlation) in addition to $\bar{r}$ (uncorrected sample-size-weighted mean correlation). We computed corrected $95 \%$ confidence intervals to check the statistical significance of effect sizes. A corrected $95 \%$ confidence interval that does not pass through zero indicates the statistical significance of an effect size at 0.05 level. We calculated both $\operatorname{Var}_{\text {art }} \%$ statistic and corrected $80 \%$ credibility interval to assess the presence of moderators. We considered the potential presence of moderators in a meta-analytic distribution when statistical artifacts explain less than $75 \%$ of the effect sizes' variance (i.e., Varart $\%<75 \%$ ). Further, a wide $80 \%$ credibility interval is also an indicator of potential presence of moderators. Hunter and Schmidt's subgroup analyses were performed to examine moderator effects.

\section{Results}

\section{Main Effect}

The meta-analytic findings were displayed in Table 2. We found that hospitality workers' EI is positively related to their job performance $(\hat{\rho}=0.54)$ because the $95 \%$ confidence interval ranges from 0.42 to 0.65 and does not pass through zero. Hypothesis 1 is thus supported. The $\operatorname{Var}_{a r t} \%$ statistic for the relationship between hospitality workers' EI and job performance is $7 \%$, which is substantially less than $75 \%$ and thus suggests the potential presence of moderators. 
Insert Table 2 about here

\section{Moderator Effect}

We conducted subgroup analyses to assess a series of moderators. The last column of Table 2 displayed the results for moderator analyses. The relationship between hospitality workers' EI and job performance is stronger when the percent of married subjects is low than when the percent of married subjects is high $(\Delta \hat{\rho}=0.37, p<0.05)$. Hypothesis 4 is thus supported. The same procedures were repeated to examine all other moderators. The relationship between hospitality workers' EI and job performance is stronger in feminine cultures (Hypothesis 6). However, this relationship does not differ across gender (Hypothesis 2), education levels (Hypothesis 3), between individualistic and collectivistic cultures (Hypothesis 5), between low and high-power distance cultures (Hypothesis 7), and between low and high uncertainty avoidance cultures (Hypothesis 8); hence, these hypotheses are not supported. We tabulated all hypotheses and results in Table 3.

Insert Table 3 about here

\section{Publication Bias Analyses}

We performed two publication bias analyses, trim-and-fill analysis and Egger's test of the intercept. Trim-and-fill analysis showed that two samples were imputed on the right side of the funnel plot, meaning that studies having positive and larger effect sizes may be missing. Further, the difference between observed mean correlation and adjusted observed mean correlation is much less than $20 \%$, denoting that the degree of publication bias is negligible. Second, Egger's test of the intercept yielded an intercept of -2.57 , which is statistically non-significant at 0.05 level. This test demonstrated the absence of publication bias. In sum, publication bias is negligible or absent. 


\section{Discussion and Conclusions}

\section{Conclusions}

EI has been widely recognized as playing a very critical role in hospitality industry because the work roles in the hospitality industry are especially emotionally demanding. Using meta-analytic techniques, we found support for the important role of EI in determining hospitality workers' job performance. In addition, the performance effect of EI is stronger when percent of married subjects is low and in feminine cultures. Despite this heightened effect, the performance effect of EI remains consistently positive and statistically significant across gender, educational level, marital status, and some national cultures. Future studies may use our research findings as a roadmap to identify more moderators that may condition the performance effect of EI.

\section{Theoretical Implications}

The jobs in the hospitality industry are highly emotionally demanding due to hospitality workers' frequent contact with customers. Although EI is considered as a critical aspect of service interactions (Viglia and Rodrigo, 2020) and organizational performance (Jung and Yoon, 2016), the heterogeneity in the distribution of effect sizes for the relationship between EI and hospitality workers' job performance across studies is quite substantial. To answer the call to build cumulative evidence in the hospitality literature (Kim et al., 2018), we performed a metaanalysis to examine the relationship between EI and hospitality workers' job performance and found that this relationship is positive and statistically significant $(\hat{\rho}=0.54)$. We thus found support for the notion that EI indeed plays a crucial role in influencing hospitality workers' job performance. By way of comparison, the O'Boyle et al. (2011) meta-analysis found that across all occupations that the corrected correlation between EI and job performance was .28, which is 
considerably lower than the 0.54 relationship we found for EI and job performance for hospitality workers. Thus, our results confirm our expectations that EI would be especially important to job performance for hospitality workers. Our research adds to a large body of prior research by corroborating the role of EI in boosting hospitality workers' job performance (e.g., Chen and Wang, 2019; Genc and Kozak, 2020; Han et al., 2017; Koc and Boz, 2020; Langhorn, 2004; Lee and Ok, 2012; Scott-Halsell et al., 2008).

Our findings demonstrated that the performance effect of EI is consistently positive and statistically significant across collectivistic cultures, feminine and masculine cultures, high power distance cultures, and high uncertainty avoidance cultures. For the other 3 cultures, the corrected correlations are $0.28,0.28$, and 0.42 , but the lower confidence boundary barely includes zero $(-0.07 ;-0.07$; and -0.02$)$, thus the effects are only borderline. The performance effect of EI is stronger in feminine cultures than in masculine cultures because feminine cultures call for more frequent use of EI to enable hospitality workers to be modest, caring, and sympathetic (Gunkel et al., 2014; Hofstede, 2011). Emmerling and Boyatzis (2012) indicated that the universal versus relativistic values of EI might require further exploration. Our findings supported both schools of thoughts regarding the cross-cultural validity of EI by demonstrating that the validity of EI in predicting hospitality workers' job performance is largely universal along with a relatively stronger validity in feminine cultures (compared to that in masculine cultures).

Our results are also consistent with other cross-cultural meta-analytical studies on the universal relationship between EI and job performance. For example, Miao et al. (2020) examined the cross-cultural moderators of EI—organizational citizenship behavior and EIcounterproductive work relationships. For organizational citizenship behavior, they found that EI 
was universally important for all cultures, and almost universally important for counterproductive work behavior. Moreover, their study found that for EI-counterproductive work behavior that the relationships were stronger in feminine cultures than in masculine cultures, again matching our findings. However, unlike this study, the Miao et al. (2020) metaanalysis also found that other cultural dimensions also showed moderator effects for EIorganizational citizenship behavior and EI - counterproductive work behavior. In addition, the Miao et al. (2018b) meta-analysis on leader EI and subordinate task performance and organizational citizenship behavior also found that EI was universally valued across cultures. This current study found statistically significant positive effects of EI on performance for 5 cultural dimensions, and borderline positive effects for the remaining 3 cultural dimensions examined; however, when combined with the results from the other 2 meta-analyses it makes sense to conclude that EI universally positively influences job performance across cultures.

We found that the relationship between EI and hospitality workers' job performance does not significantly vary by gender. These findings are consistent with the research that finds that men and women are equal in their EI and emotional competencies (Taylor and Hood, 2011). In addition, our findings are consistent with another meta-analyses on EI (Miao et al., 2017c), which found that males and females equally benefitted from using EI to enhance their job satisfaction. We believe our findings support gender equality in the workplace and indicate that men and women are equally competent in using EI. Gender-related research is a popular and important area of inquiry and more research needs to be done on gender in the hospitality industry (e.g., Jung and Yoon, 2014; Kara et al., 2012, 2018; Segovia-Perez et al., 2019).

We also found that both well-educated and less educated subjects may equally benefit from EI to boost their job performance. Based on the information reported by the included 
primary studies, the education level in the present study is coded as the percent of subjects having college level degree or above. It is possible that the null moderator effect of educational level may be because the education under investigation is general college education. Such general college education may or may not cover the knowledge or skill development courses related to hospitality work or to EI development. We encourage future research to examine whether EI-focused education or training programs (e.g., Boyatzis and Saatcioglu, 2008) may increase hospitality workers' competency to use their EI to improve their job performance.

We found that marital status is a significant moderator, suggesting that the relationship between EI and hospitality workers' job performance is stronger when percent of married subjects is low. Because single hospitality workers lack the social, emotional, and financial resources that come from being married, EI plays a more important role in their job performance. Most likely this is because EI helps them cope with the stress that comes from being single. This finding sends an important message to managerial practitioners that it is important to support their single workers' emotional needs.

\section{Practical Implications}

Training and selection for employees is important in the hospitality industry in that hospitality workers have direct contact with customers, and they play a vital role in influencing the performance of an organization (Anderson et al., 2003). Our meta-analysis supports this notion by showing that EI has a positive and statistically significant relationship with hospitality workers' job performance. This effect is consistently positive and statistically significant across gender, educational level, marital status, and some national cultural dimensions. As the comparison with the O’Boyle et al. (2011) meta-analysis results demonstrated, the beneficial effects of EI on job performance are considerably stronger in the hospitality industry than for 
most other industries. Hence, it is especially important that practicing managers in the hospitality industry assign EI trainings to their existing employees and/or hire emotionally intelligent employees to staff their organizations (Boyatzis, 2009; Hodzic et al., 2018). These

recommendations are consistent with the research in the hospitality industry that emphasizes the importance of soft skills training for talent management and hotel employees (Kim et al., 2011; Self et al., 2019).

Our findings also have profound cross-cultural implications for managers from multinational corporations in the hospitality industry because we found that the performance effect of EI is stronger in feminine cultures. Managers in the hospitality industry from feminine cultures should be especially vigilant in implementing HR policies or practices that capitalize on the positive performance effect of EI. Although the effect of EI on hospitality workers' job performance is strongest in feminine cultures, with a corrected correlation of 0.59 , the effect size in masculine cultures is still hefty at 0.33 . Our results, combined with the results of other metaanalyses (Miao et al., 2018b, 2020), indicate that EI has beneficial effects on job performance in every culture. Thus, we recommend that hospitality managers and HR policy makers should support EI selection and training programs in every culture.

\section{Limitations and Future Directions}

Due to the absence of available studies that used ability EI, we were unable to analyze ability EI in our study. We encourage future research to investigate the performance effect of ability EI and in the hospitality industry to get a full picture of the performance effect of EI in hospitality industry. A subset of included studies in our meta-analysis used self-reported ratings of job performance. Although using self-reported ratings of job performance may not be an ideal approach, a prior meta-analysis demonstrated that effect sizes are not inflated due to the use of 
self-reported measures of job performance (Churchill et al., 1985). We encourage future research to use supervisor ratings of job performance or multisource ratings of job performance to minimize the biases which may be introduced as a result of rating sources.

It is quite possible that the EI-job performance relationship might vary according to whether hospitality workers are front of the house line workers, or back-of-the house workers or managers and executives. As the number of studies grow, it should be possible to include the type of hospitality position in tests for moderation effects. Moreover, it is likely that job security and economic conditions may influence the degree that front line service staff feel motivated to use their EI skills to provide superior customer service and "service with a smile". Under high levels of job security and with low unemployment rates, staff may be less motivated and may even feel free to be contemptuous to customers. Thus, future researchers could test whether job security and unemployment rates moderate the EI—service performance relationship.

\section{References $^{1}$}

Anderson, B. A., Provis, C. and Chappel, S. J. (2003), "The selection and training of workers in the tourism and hospitality industries for the performance of emotional labour", Journal of Hospitality and Tourism Management, Vol. 10 No. 1, pp. 1-13.

Andrei, F., Siegling, A. B., Aloe, A. M., Baldaro, B. and Petrides, K. V. (2016), “The incremental validity of the Trait Emotional Intelligence Questionnaire (TEIQue): A systematic review and meta-analysis", Journal of Personality Assessment, Vol. 98 No. 3 , pp. 261-276.

Ashforth, B. E. and Humphrey, R. H. (1993), "Emotional labor in service roles: The influence of identity", Academy of Management Review, Vol. 18 No. 1, pp. 88-115.

Ashkanasy, N. M., Humphrey, R. H. and Huy, Q. N. (2017), "Integrating emotions and affect in theories of management", Academy of Management Review, Vol. 42 No. 2, pp. 175-189.

Bae, T. J., Qian, S., Miao, C. and Fiet, J. O. (2014), “The relationship between entrepreneurship education and entrepreneurial intentions: A meta-analytic review", Entrepreneurship Theory and Practice, Vol. 38 No. 2, pp. 217-254.

\footnotetext{
${ }^{1}$ The references for the studies that are included in the present meta-analysis are marked with asterisks $(*)$.
} 
Baum, T. (2019), "Does the hospitality industry need or deserve talent?", International Journal of Contemporary Hospitality Management, Vol. 31 No. 10, pp. 3823-3837.

Boyatzis, R. E. and Saatcioglu, A. (2008), “A 20-year view of trying to develop emotional, social and cognitive intelligence competencies in graduate management education", Journal of Management Development, Vol. 27 No. 1, pp. 92-108.

Boyatzis, R. E. (2009), “Competencies as a behavioral approach to emotional intelligence”, Journal of Management Development, Vol. 28 No. 9, pp. 749-770.

Boyatzis, R. E., Good, D. and Massa, R. (2012), "Emotional, social, and cognitive intelligence and personality as predictors of sales leadership performance", Journal of Leadership \& Organizational Studies, Vol. 19 No. 2, pp. 191-201.

Boyatzis, R. E., Smith, M. L., Van Oosten, E. and Woolford, L. (2013), “Developing resonant leaders through emotional intelligence, vision and coaching", Organizational Dynamics, Vol. 42 No. 1, pp. 17-24.

Boyatzis, R. E. (2016), "Commentary on Ackley (2016): Updates on the ESCI as the behavioral level of emotional intelligence", Consulting Psychology Journal: Practice and Research, Vol. 68 No. 4, pp. 287-293.

Cairney, J., Boyle, M., Offord, D. R. and Racine, Y. (2003), "Stress, social support and depression in single and married mothers", Social Psychiatry and Psychiatric Epidemiology, Vol. 38 No. 8, pp. 442-449.

Chang, W., Liu, A., Wang, X. and Yi, B. (2020), "Meta-analysis of outcomes of leader-member exchange in hospitality and tourism: What does the past say about the future?", International Journal of Contemporary Hospitality Management, Vol. 32 No. 6, pp. 2155-2173.

Chen, H. T. and Wang, C. H. (2019). "Incivility, satisfaction and turnover intention of tourist hotel chefs", International Journal of Contemporary Hospitality Management, Vol. 31, No. 5, pp. 2034-2053.

Cherniss, C. (2001), "Emotional intelligence and organizational effectiveness", In C. Cherniss \& D. Goleman (Eds.), The emotionally intelligent workplace (pp. 3-12). San Francisco: Jossey-Bass.

Cho, M., Bonn, M. A., Han, S. J. and Lee, K. H. (2016), "Workplace incivility and its effect upon restaurant frontline service employee emotions and service performance", International Journal of Contemporary Hospitality Management, Vol. 28 No. 12, pp. 2888-2912. 
Choi, H. M., Mohammad, A. A. and Kim, W. G. (2019), "Understanding hotel frontline employees' emotional intelligence, emotional labor, job stress, coping strategies and burnout", International Journal of Hospitality Management, Vol. 82, pp. 199-208.

Churchill Jr, G. A., Ford, N. M., Hartley, S. W. and Walker Jr, O. C. (1985), "The determinants of salesperson performance: A meta-analysis", Journal of Marketing Research, Vol. 22 No. 2, pp. 103-118.

Døving, E. and Gooderham, P. N. (2008), "Dynamic capabilities as antecedents of the scope of related diversification: The case of small firm accountancy practices", Strategic Management Journal, Vol. 29 No. 8, pp. 841-857.

Emmerling, R. J. and Boyatzis, R. E. (2012), "Emotional and social intelligence competencies: Cross cultural implications", Cross Cultural Management: An International Journal, Vol. 19 No. 1, pp. 4-18.

Frederickson, N., Petrides, K. V. and Simmonds, E. (2012), "Trait emotional intelligence as a predictor of socioemotional outcomes in early adolescence", Personality and Individual Differences, Vol. 52 No. 3, pp. 323-328.

Genc, V. and Kozak, M. A. (2020), "Emotional and social competence in the aestheticization of labor in the restaurant industry", International Journal of Contemporary Hospitality Management, Vol. 32 No. 3, pp. 1201-1225.

Goleman, D. (1995), “Emotional intelligence: Why it can matter more than IQ”, New York, NY: Bantam Books.

Goleman, D., Boyatzis, R. E. and McKee, A. (2013), "Primal leadership: Unleashing the power of emotional intelligence", Harvard Business Press.

Gui, C., Luo, A., Zhang, P. and Deng, A. (2020), "A meta-analysis of transformational leadership in hospitality research", International Journal of Contemporary Hospitality Management, Vol. 32 No. 6, pp. 2137-2154.

Gültekin, S. and Icigen, E. (2019), "A research on professional tour guides emotional intelligence and problem-solving skills", Journal of Quality Assurance in Hospitality \& Tourism, Vol. 20 No. 2, pp. 230-258.

Gunkel, M., Schlägel, C. and Engle, R. L. (2014), “Culture's influence on emotional intelligence: An empirical study of nine countries", Journal of International Management, Vol. 20 No. 2, pp. 256-274.

Han, S. J., Kim, W. G. and Kang, S. (2017), "Effect of restaurant manager emotional intelligence and support on front-of-house employees' job satisfaction", International Journal of Contemporary Hospitality Management, Vol. 29 No. 11, pp. 2807-2825. 
*Hanzaee, K. and Mirvaisi, M. (2013), "A survey on impact of emotional intelligence, organizational citizenship behaviors and job satisfaction on employees' performance in Iranian hotel industry", Management Science Letters, Vol. 3 No. 5, pp. 1395-1402.

Hobfoll, S. E., (1989), "Conservation of resources: a new attempt at conceptualizing stress", American Psychologist, Vol. 44 No. 3, 513-524.

Hodzic, S., Scharfen, J., Ripoll, P., Holling, H. and Zenasni, F. (2018), "How efficient are emotional intelligence trainings: A meta-analysis", Emotion Review, Vol. 10 No. 2, pp. 138-148.

Hofstede, G., Hofstede, G. J. and Minkov, M. (2010), “Cultures and organizations: Software of the mind", McGraw-Hill.

Hofstede, G. (2011), "Dimensionalizing cultures: The Hofstede model in context", Online Readings in Psychology and Culture, Vol. 2 No. 1, Article 8.

*Hsu, S. W., Chang, H. H., Wu, C. M. and Chen, K. L. (2016), “Does employees' emotional intelligence in the international tourist hotels matter? Emotional intelligence as a moderator of organizational climate, service quality and job performance", Commerce \& Management Quarterly, Vol. 17 No. 4, pp. 435-466.

Humphrey, R. H., Ashforth, B. E. and Diefendorff, J. M. (2015), "The bright side of emotional labor”, Journal of Organizational Behavior, Vol. 36 No. 6, pp. 749-769.

Humphrey, R. H., Pollack, J. M. and Hawver, T. H. (2008), "Leading with emotional labor", Journal of Managerial Psychology, Vol. 23 No. 2, pp. 151-168.

*Jane, C. A. and Gerald, W. A. (2018), "Impact of emotional intelligence on performance of employees with reference to Femina hotel in Trichy", International Journal of Advance Research in Computer Science and Management Studies, Vol. 6 No. 2, pp. 14-19.

Jung, H. S., and Yoon, H. H. (2014), "Moderating role of hotel employees' gender and job position on the relationship between emotional intelligence and emotional labor", International Journal of Hospitality Management, Vol. 43, pp. 47-52.

Jung, H. S. and Yoon, H. H. (2016), "Why is employees' emotional intelligence important? The effects of EI on stress-coping styles and job satisfaction in the hospitality industry", International Journal of Contemporary Hospitality Management, Vol. 28 No. 8, pp. 1649-1675.

Kara, D., Kim, H. L., Lee, G. and Uysal, M. (2018), “The moderating effects of gender and income between leadership and quality of work life (QWL)", International Journal of Contemporary Hospitality Management, Vol. 30 No. 3, pp. 1419-1435. 
Kara, D., Uysal, M., \& Magnini, V. P. (2012). Gender differences on job satisfaction of the fivestar hotel employees. International Journal of Contemporary Hospitality Management, Vol. 24 No. 7, pp. 1047-1065.

*Karimi, J. M. N. (2014), "Effects of emotional intelligence on employee performance in the hotel industry in Kenya", The International Journal of Business \& Management, Vol. 2 No. 12, pp. 6-14.

Kellett, J. B., Humphrey, R. H. and Sleeth, R. G. (2002), “Empathy and complex task performance: Two routes to leadership", The Leadership Quarterly, Vol. 13 No. 5, pp. 523-544.

Kim, C. S., Bai, B. H., Kim, P. B. and Chon, K. (2018), "Review of reviews: A systematic analysis of review papers in the hospitality and tourism literature", International Journal of Hospitality Management, Vol. 70, pp. 49-58.

Kim, H. and Qu, H. (2019), "Employees' burnout and emotional intelligence as mediator and moderator in the negative spiral of incivility", International Journal of Contemporary Hospitality Management, Vol. 31 No. 3, pp. 1412-1431.

*Kim, H.-Y. and Ko, J.-Y. (2014), "The effects of emotional intelligence on job performance of the hotel F\&B employees", Korean Journal of Hotel Administration, Vol. 23 No. 1, pp. 181-198.

Kim, J. S., Erdem, M., Byun, J. and Jeong, H. (2011), “Training soft skills via e-learning: international chain hotels", International Journal of Contemporary Hospitality Management, Vol. 23 No. 6, pp. 739-763.

*Kim, T., Yoo, J. J.-E., Lee, G. and Kim, J. (2012), "Emotional intelligence and emotional labor acting strategies among frontline hotel employees", International Journal of Contemporary Hospitality Management, Vol. 24 No. 7, pp. 1029-1046.

Kirkman, B. L., Chen, G., Farh, J. L., Chen, Z. X. and Lowe, K. B. (2009), "Individual power distance orientation and follower reactions to transformational leaders: A cross-level, cross-cultural examination", Academy of Management Journal, Vol. 52 No. 4, pp. 744764.

Koc, E. and Boz, H. (2020), “Development of hospitality and tourism employees' emotional intelligence through developing their emotion recognition abilities", Journal of Hospitality Marketing \& Management, Vol. 29 No. 2, pp. 121-138.

Kong, H., Jiang, X., Chan, W. and Zhou, X. (2018), "Job satisfaction research in the field of hospitality and tourism", International Journal of Contemporary Hospitality Management, Vol. 30 No. 5, pp. 2178-2194. 
Kong, H., Yuan, Y., Baruch, Y., Bu, N., Jiang, X. and Wang, K. (2021), "Influences of artificial intelligence (AI) awareness on career competency and job burnout", International Journal of Contemporary Hospitality Management, Vol. ahead-of-print No. ahead-ofprint.

*Koronios, K., Kriemadis, A., Dimitropoulos, P., Douvis, I., Papadopoulos, A. and Manousaridou, G. (2019), "Emotional intelligence of employees in the hospitality sector: Exploring its effects on job satisfaction and performance", In V. Katsoni and M. SegarraOña (Eds.), Smart Tourism as a Driver for Culture and Sustainability (pp. 515 - 525). Springer Proceedings in Business and Economics. Springer, Cham.

*Kvári, E. M. (2016), “Don't worry, be emotionally intelligent Hotel functional managers' trait emotional intelligence and its relation to task and contextual performance within organisational culture in Hungary", Unpublished doctoral dissertation, University of Derby.

*Langhorn, S. (2004), "How emotional intelligence can improve management performance", International Journal of Contemporary Hospitality Management, Vol. 16 No. 4, pp. 220230.

Lee, J. J. and Ok, C. (2012), "Reducing burnout and enhancing job satisfaction: Critical role of hotel employees' emotional intelligence and emotional labor", International Journal of Hospitality Management, Vol. 31 No. 4, pp. 1101-1112.

Lee, J. J., and Ok, C. M. (2014), “Understanding hotel employees' service sabotage: Emotional labor perspective based on conservation of resources theory", International Journal of Hospitality Management, Vol. 36, 176-187.

Lee, L. and Madera, J.M. (2019), "A systematic literature review of emotional labor research from the hospitality and tourism literature", International Journal of Contemporary Hospitality Management, Vol. 31 No. 7, pp. 2808-2826.

Li, Y. and Huang, S. S. (2017), "Hospitality service climate, employee service orientation, career aspiration and performance: A moderated mediation model", International Journal of Hospitality Management, Vol. 67, pp. 24-32.

Lipsey, M. W. and Wilson, D. B. (2001), "Practical meta-analysis", Thousand Oaks, CA: Sage Publications.

Liu, J. and Cho, S. (2018), "Interaction effect of display rules and emotional intelligence on hotel managers' and non-managers' work engagement”, International Journal of Contemporary Hospitality Management, Vol. 30 No. 3, pp. 1903-1919.

Martins, A., Ramalho, N. and Morin, E. (2010), "A comprehensive meta-analysis of the relationship between emotional intelligence and health", Personality and Individual Differences, Vol. 49 No. 6, pp. 554-564. 
Martin, B. C., McNally, J. J. and Kay, M. J. (2013), "Examining the formation of human capital in entrepreneurship: A meta-analysis of entrepreneurship education outcomes", Journal of Business Venturing, Vol. 28 No. 2, pp. 211-224.

Mayer, J. D., Salovey, P., Caruso, D. R., \& Sitarenios, G. (2003), "Measuring emotional intelligence with the MSCEIT V2.0”, Emotion, Vol. 3 No. 1, pp.97-105.

Miao, C., Humphrey, R. H. and Qian, S. (2016), "Leader emotional intelligence and subordinate job satisfaction: A meta-analysis of main, mediator, and moderator effects", Personality and Individual Differences, Vol. 102, pp. 13-24.

Miao, C., Humphrey, R. H. and Qian, S. (2017a), "A meta-analysis of emotional intelligence and work attitudes”, Journal of Occupational and Organizational Psychology, Vol. 90 No. 2, pp. 177-202.

Miao, C., Humphrey, R. H. and Qian, S. (2017b), "Are the emotionally intelligent good citizens or counterproductive? A meta-analysis of emotional intelligence and its relationships with organizational citizenship behavior and counterproductive work behavior", Personality and Individual Differences, Vol. 116, pp. 144-156.

Miao, C., Humphrey, R. H., and Qian, S. (2017c), “A meta-analysis of emotional intelligence effects on job satisfaction mediated by job resources, and a test of moderators", Personality and Individual Differences, Vol. 116, pp. 281-288.

Miao, C., Rutherford, M. W. and Pollack, J. M. (2017d), "An exploratory meta-analysis of the nomological network of bootstrapping in SMEs", Journal of Business Venturing Insights, Vol. 8, pp. 1-8.

Miao, C., Humphrey, R. H., \& Qian, S. (2018a). Emotional Intelligence and Authentic Leadership: A Meta-Analysis. Leadership \& Organization Development Journal, 39, 679-690.

Miao, C., Humphrey, R. H. and Qian, S. (2018b), “A cross-cultural meta-analysis of how leader emotional intelligence influences subordinate task performance and organizational citizenship behavior", Journal of World Business, Vol. 53 No. 4, pp. 463-474.

Miao, C., Humphrey, R. H. and Qian, S. (2020), "The cross-cultural moderators of the influence of emotional intelligence on organizational citizenship behavior and counterproductive work behavior", Human Resource Development Quarterly, Vol. 31 No. 2, pp. 213-233.

Min, J. C. (2011), “Tour guides and emotional intelligence”, Annals of Tourism Research, Vol. 38 No. 1, pp. 322-325. 
Moreo, A., Woods, R., Sammons, G. and Bergman, C. (2019), "Connection or competence: Emotional labor and service quality's impact on satisfaction and loyalty", International Journal of Contemporary Hospitality Management, Vol. 31 No. 1, pp. 330-348.

Nisa, C., Varum, C. and Botelho, A. (2017), "Promoting sustainable hotel guest behavior: A systematic review and meta-analysis", Cornell Hospitality Quarterly, Vol. 58 No. 4, pp. 354-363.

O'Boyle, E. H., Humphrey, R. H., Pollack, J. M., Hawver, T. H. and Story, P. A. (2011), “The relation between emotional intelligence and job performance: A meta-analysis", Journal of Organizational Behavior, Vol. 32 No. 5, pp. 788-818.

Peterson, R. A. and Brown, S. P. (2005), "On the use of beta coefficients in meta-analysis", Journal of Applied Psychology, Vol. 90 No. 1, pp. 175-181.

Petrides, K. V. and Furnham, A. (2001), “Trait emotional intelligence: Psychometric investigation with reference to established trait taxonomies", European Journal of Personality, Vol. 15 No. 6, pp. 425-448.

Petrides, K. V., Frederickson, N. and Furnham, A. (2004), “The role of trait emotional intelligence in academic performance and deviant behavior at school", Personality and Individual Differences, Vol. 36 No. 2, pp. 277-293.

Petrides, K. V., Pita, R. and Kokkinaki, F. (2007), “The location of trait emotional intelligence in personality factor space”, British Journal of Psychology, Vol. 98 No. 2, pp. 273-289.

Petrides, K. V., Mikolajczak, M., Mavroveli, S., Sanchez-Ruiz, M. J., Furnham, A. and PérezGonzález, J. C. (2016), “Developments in trait emotional intelligence research”, Emotion Review, Vol. 8 No. 4, pp. 335-341.

Petrides, K. V. (2017), "Intelligence, emotional”, Reference Module in Neuroscience and Biobehavioral Psychology, pp. 1-6.

*Prentice, C. and King, B. (2011), "The influence of emotional intelligence on the service performance of casino frontline employees", Tourism and Hospitality Research, Vol. 11 No. 1, pp. 49-66.

*Prentice, C. and King, B. E. (2013a), "Impacts of personality, emotional intelligence and adaptiveness on service performance of casino hosts: A hierarchical approach", Journal of Business Research, Vol. 66 No. 9, pp. 1637-1643.

*Prentice, C. and King, B. E. (2013b), "Emotional intelligence and adaptability-service encounters between casino hosts and premium players", International Journal of Hospitality Management, Vol. 32, pp. 287-294. 
Schmidt, F. L. and Hunter, J. E. (2015), “Methods of meta-analysis: Correcting error and bias in research findings", Sage Publications, Inc.

Schutte, N. S., Malouff, J. M., Thorsteinsson, E. B., Bhullar, N. and Rooke, S. E. (2007), “A meta-analytic investigation of the relationship between emotional intelligence and health", Personality and Individual Differences, Vol. 42 No. 6, pp. 921-933.

Scott-Halsell, S. A., Blum, S. C. and Huffman, L. (2008), “A study of emotional intelligence levels in hospitality industry professionals", Journal of Human Resources in Hospitality \& Tourism, Vol. 7 No. 2, 135-152.

Segovia-Perez, M., Figueroa-Domecq, C., Fuentes-Moraleda, L. and Munoz-Mazon, A. (2019), "Incorporating a gender approach in the hospitality industry: Female executives' perceptions", International Journal of Hospitality Management, Vol. 76, pp. 184-193.

Self, T. T., Gordon, S. and Jolly, P. M. (2019), “Talent management: A Delphi study of assessing and developing GenZ hospitality leaders", International Journal of Contemporary Hospitality Management, Vol. 31 No. 10, pp. 4126-4149.

Shani, A., Uriely, N., Reichel, A. and Ginsburg, L. (2014), "Emotional labor in the hospitality industry: The influence of contextual factors", International Journal of Hospitality Management, Vol. 37, pp. 150-158.

Siegling, A. B., Vesely, A. K., Saklofske, D. H., Frederickson, N. and Petrides, K. V. (2015), "Incremental validity of the trait emotional intelligence questionnaire-adolescent short form (TEIQue-ASF)", European Journal of Psychological Assessment, Vol. 33 No. 1, pp. $65-74$.

*Tahir, I. M. and Monil, M. (2015), "Preliminary study of emotional intelligence and communication satisfaction on job performance: A study on Malaysian hotel industry", Journal of Human Capital Development, Vol. 8 No. 2, pp. 75-82.

Taylor, S. N. and Hood, J. N. (2011), "It may not be what you think: Gender differences in predicting emotional and social competence," Human Relations, Vol. 64 No. 5, pp. 627652.

*Tekin, O. A. and Gündoĝan, H. (2017), "The relationship between emotional intelligence and job performance: A study on a five-star hotel employees", Marmara Business Review, Vol. 2 No. 1, pp. 51-69.

Tett, R. P. and Burnett, D. D. (2003), “A personality trait-based interactionist model of job performance”, Journal of Applied Psychology, Vol. 88 No. 3, pp. 500-517.

*Tsai, C. T. and Lee, Y. J. (2014), "Emotional intelligence and employee creativity in travel agencies", Current Issues in Tourism, Vol. 17 No. 10, pp. 862-871. 
Tsaur, S. H. and Ku, P. S. (2019), “The effect of tour leaders' emotional intelligence on tourists' consequences", Journal of Travel Research, Vol. 58 No. 1, pp. 63-76.

van der Linden, D., Pekaar, K. A., Bakker, A. B., Schermer, J. A., Vernon, P. A., Dunkel, C. S. and Petrides, K. V. (2017), "Overlap between the general factor of personality and emotional intelligence: A meta-analysis", Psychological Bulletin, Vol. 143 No. 1, pp. 3652.

van Steenbergen, E. F., Kluwer, E. S. and Karney, B. R. (2014), "Work-family enrichment, work-family conflict, and marital satisfaction: A dyadic analysis", Journal of Occupational Health Psychology, Vol. 19 No. 2, pp. 182-194.

Viglia, G. and Rodrigo, P. (2020), "Emotional intelligence in tourism and hospitality", Tourism Management, Vol. 77, pp. 1-2.

Walsh, K., Chang, S. and Tse, E. C. Y. (2015), 'Understanding students' intentions to join the hospitality industry: The role of emotional intelligence, service orientation, and industry satisfaction”, Cornell Hospitality Quarterly, Vol. 56 No. 4, pp. 369-382.

Waite, L. J. and Gallagher, M. (2000), “The case for marriage: Why married people are happier, healthier and better off financially", New York: Doubleday.

Wen, J., Huang, S. S. and Hou, P. (2019), "Emotional intelligence, emotional labor, perceived organizational support, and job satisfaction: A moderated mediation model", International Journal of Hospitality Management, Vol. 81, pp. 120-130.

$\mathrm{Xu}$, S. and Cao, Z. C. (2019), “Antecedents and outcomes of work-nonwork conflict in hospitality: A meta-analysis", International Journal of Contemporary Hospitality Management, Vol. 31 No. 10, pp. 3919-3942.

Yang, Y., Park, S. and Hu, X. (2018), "Electronic word of mouth and hotel performance: A meta-analysis", Tourism Management, Vol. 67, pp. 248-260. 
Figure 1. Conceptual Model of Hospitality Workers' EI and Job Performance

\begin{tabular}{|l|l|l|}
\hline \multicolumn{1}{|c|}{\begin{tabular}{|l|}
\multicolumn{1}{|c|}{ Demographic Moderators } \\
Hypothesis 2: Gender \\
Hypothesis 3: Educational Level \\
Hypothesis 4: Marital Status
\end{tabular}} & \begin{tabular}{l}
\multicolumn{1}{c|}{ National Cultural Moderators } \\
Hypothesis 5: Individualism vs. Collectivism \\
Hypothesis 6: Masculinity vs. Femininity \\
Hypothesis 7: Power Distance \\
Hypothesis 8: Uncertainty Avoidance
\end{tabular} \\
\hline \begin{tabular}{|l|l|}
\hline Hospitality Workers' \\
Emotional Intelligence
\end{tabular} & Hypothesis 1 & \begin{tabular}{|} 
Hospitality Workers' Job \\
Performance
\end{tabular} \\
\hline
\end{tabular}


Table 1. Summary Table of Variable Coding and Definitions

\section{Variable Names}

EI

Hospitality Workers' Job

Performance

Gender

Education

Marital Status

Cultural Dimensions
Variable Coding and Definitions

Trait EI: self-perceptions of emotional abilities and emotion-related dispositions (e.g., Petrides \& Furnham, 2001; Petrides et al., 2016).

Service performance and other task performance measures.

Coded the percent of male subjects and performed a median split to allocate samples into maledominated and female-dominated subgroups.

Coded the percent of subjects having college level degree or above and conducted a median split to assign samples into high and low education level subgroups.

Coded the percent of subjects who are married and performed a median split to allocate samples into high and low subgroups.

Utilized Hofstede cultural dimensions (Hofstede, Hofstede, \& Minkov, 2010) to code individualism (versus collectivism), masculinity (versus femininity), power distance, and uncertainty avoidance. 
Table 2. Meta-Analysis Results for the Relationship between EI and Hospitality Workers' Job Performance

\begin{tabular}{|c|c|c|c|c|c|c|c|c|c|c|c|c|}
\hline & $k$ & $N$ & $\bar{r}$ & $S D_{r}$ & $\hat{\rho}$ & $S D_{\rho}$ & CI LL & CI UL & CV LL & CV UL & $\operatorname{Var}_{a r t} \%$ & Moderator Effect \\
\hline $\begin{array}{c}\text { H1: EI - Hospitality Workers' } \\
\text { Job Performance }\end{array}$ & 15 & 3,086 & 0.46 & 0.22 & 0.54 & 0.23 & 0.42 & 0.65 & 0.24 & 0.83 & $7 \%$ & \\
\hline \multicolumn{13}{|l|}{ H2: Gender } \\
\hline a. Male-dominated & 6 & 1,466 & 0.36 & 0.19 & 0.43 & 0.20 & 0.26 & 0.59 & 0.17 & 0.68 & $9 \%$ & - \\
\hline b. Female-dominated & 6 & 1,425 & 0.54 & 0.21 & 0.63 & 0.19 & 0.47 & 0.78 & 0.38 & 0.87 & $7 \%$ & - \\
\hline \multicolumn{13}{|l|}{ H3: Educational Level } \\
\hline a. High & 5 & 1,209 & 0.44 & 0.11 & 0.54 & 0.10 & 0.44 & 0.63 & 0.41 & 0.66 & $29 \%$ & - \\
\hline b. Low & 5 & 1,296 & 0.53 & 0.25 & 0.60 & 0.25 & 0.38 & 0.82 & 0.28 & 0.91 & $4 \%$ & - \\
\hline \multicolumn{13}{|l|}{ H4: Marital Status } \\
\hline a. High & 3 & 843 & 0.29 & 0.08 & 0.35 & 0.09 & 0.23 & 0.47 & 0.23 & 0.47 & $34 \%$ & $\mathrm{~b}$ \\
\hline b. Low & 3 & 845 & 0.65 & 0.20 & 0.72 & 0.19 & 0.50 & 0.93 & 0.48 & 0.96 & $4 \%$ & $\mathrm{a}$ \\
\hline \multicolumn{13}{|l|}{ H5: IDV } \\
\hline a. Individualism & 2 & 270 & 0.24 & 0.24 & 0.28 & 0.24 & -0.07 & 0.63 & -0.02 & 0.59 & $13 \%$ & - \\
\hline b. Collectivism & 9 & 2,178 & 0.51 & 0.23 & 0.59 & 0.23 & 0.44 & 0.74 & 0.30 & 0.88 & $5 \%$ & - \\
\hline \multicolumn{13}{|l|}{ H6: MAS } \\
\hline a. Masculinity & 5 & 529 & 0.28 & 0.18 & 0.33 & 0.18 & 0.16 & 0.50 & 0.10 & 0.56 & $26 \%$ & $\mathrm{~b}$ \\
\hline b. Femininity & 6 & 1,875 & 0.51 & 0.23 & 0.59 & 0.23 & 0.40 & 0.77 & 0.30 & 0.88 & $4 \%$ & $\mathrm{a}$ \\
\hline \multicolumn{13}{|l|}{ H7: PDI } \\
\hline a. High Power Distance & 10 & 2,236 & 0.50 & 0.23 & 0.58 & 0.23 & 0.44 & 0.73 & 0.29 & 0.88 & $6 \%$ & - \\
\hline $\begin{array}{l}\text { b. Low Power Distance } \\
\text { H8: UA }\end{array}$ & 2 & 270 & 0.24 & 0.24 & 0.28 & 0.24 & -0.07 & 0.63 & -0.02 & 0.59 & $13 \%$ & - \\
\hline a. High Uncertainty Avoidance & 8 & 2,150 & 0.50 & 0.22 & 0.58 & 0.21 & 0.43 & 0.73 & 0.30 & 0.85 & $6 \%$ & - \\
\hline b. Low Uncertainty Avoidance & 3 & 321 & 0.36 & 0.36 & 0.42 & 0.37 & -0.02 & 0.85 & -0.06 & 0.90 & $6 \%$ & - \\
\hline
\end{tabular}

Note. $k=$ number of independent samples; $N=$ sample size; $\bar{r}=$ uncorrected sample-size-weighted mean correlation; $S D_{r}=$ sample-size-weighted standard deviation of observed mean correlations; $\bar{\rho}=$ corrected sample-size-weighted mean correlation; $S D_{\rho}=$ sample-size-weighted standard deviation of corrected mean correlations; CI LL and CI UL = lower and upper bounds of corrected $95 \%$ confidence interval; CV LL and CV UL $=$ lower and upper bounds of corrected $80 \%$ credibility interval; $\mathrm{Var}_{\mathrm{art}} \%$ = percent of variance in $\bar{\rho}$ explained by statistical artifacts; $\mathrm{EI}=$ emotional intelligence. $\mathrm{H} 1-\mathrm{H} 8$ refers to Hypothesis 1 to Hypothesis 8. Moderator Effect: The letters in this column correspond to the letters in rows. These letters delineate whether effect sizes differ from one another at 0.05 level. Statistically non-significant moderators were marked with dash signs "-" in the column of Moderator Effect. 
Table 3. A Summary Table of Hypotheses and Test Results

\begin{tabular}{lc}
\hline Hypotheses & Results \\
\hline Hypothesis 1: Hospitality workers' EI is positively related to their job performance. & Supported \\
$\begin{array}{l}\text { Hypothesis 2: The relationship between hospitality workers' EI and job performance is stronger in } \\
\text { female-dominated studies than in male-dominated studies. }\end{array}$ & Not Supported \\
$\begin{array}{l}\text { Hypothesis 3: The relationship between hospitality workers' EI and job performance is stronger when } \\
\text { subjects are less educated than when subjects are well educated. }\end{array}$ & Not Supported \\
$\begin{array}{l}\text { Hypothesis 4: The relationship between hospitality workers' EI and job performance is stronger when } \\
\text { percent of married subjects is low than when percent of married subjects is high. }\end{array}$ & Supported \\
$\begin{array}{l}\text { Hypothesis 5: The relationship between hospitality workers' EI and job performance is stronger in } \\
\text { collectivistic cultures than in individualistic cultures. }\end{array}$ & Not Supported \\
$\begin{array}{l}\text { Hypothesis 6: The relationship between hospitality workers' EI and job performance is stronger in } \\
\text { feminine cultures than in masculine cultures. }\end{array}$ & Supported \\
$\begin{array}{l}\text { Hypothesis 7: The relationship between hospitality workers' EI and job performance is stronger in } \\
\text { low power distance cultures than in high power distance cultures. }\end{array}$ & Not Supported \\
$\begin{array}{l}\text { Hypothesis 8: The relationship between hospitality workers' EI and job performance is stronger in } \\
\text { high uncertainty avoidance cultures than in low uncertainty avoidance cultures. }\end{array}$ & Not Supported \\
\hline
\end{tabular}

